\title{
Temporal evolution of decaying summer first-year sea ice in the Western Weddell Sea, Antarctica
}

\author{
J.-L. Tison ${ }^{\mathrm{a}, *}$, A. Worby ${ }^{\mathrm{b}}$, B. Delille ${ }^{\mathrm{c}}$, F. Brabant ${ }^{\mathrm{a}}$, S. Papadimitriou ${ }^{\mathrm{d}}$, D. Thomas ${ }^{\mathrm{d}}$, \\ J. de Jong ${ }^{\mathrm{a}}$, D. Lannuzel ${ }^{\mathrm{b}}$, C. Haas ${ }^{\mathrm{e}, 1}$ \\ ${ }^{a}$ DSTE, Université Libre de Bruxelles, Bruxelles, Belgium \\ ${ }^{\mathrm{b}}$ ACE CRC, University of Tasmania, Hobart, Australia \\ ${ }^{\mathrm{c}}$ Unité d'Océanographie Chimique, Université de Liège, Liège, Belgium \\ ${ }^{\mathrm{d}}$ College of Natural Sciences, Bangor University, Anglesey, UK \\ ${ }^{\mathrm{e}}$ Alfred Wegener Institute for Polar and Marine Research, Bremerhaven, Germany
}

Accepted 22 December 2007

\begin{abstract}
The evolution of the main physico-chemical properties of the unflooded 90-cm-thick first-year sea-ice cover at the Ice Station POLarstern (ISPOL) "clean site" is described. ISPOL was an international experiment of the German research icebreaker R.V. Polarstern. The vessel was anchored to an ice floe for an observation period of 5 weeks, during the early summer melt onset in the Western Weddell Sea. The "clean site" was specially designed and accessed so as to prevent any trace metal contamination of the sampling area. Observations were made at 5-day intervals during December 2004 in the central part of the main floe. Results show the succession of two contrasting phases in the behavior of the brine network (brine channels, pockets, and tubes). Initially, brine salinity was higher than that of sea-water, leading to brine migration and a decrease in the mean bulk salinity of the ice cover. This process is highly favored by the already high bulk porosity (14\%), which ensures full connectivity of the brine network. Gravity drainage rather than convection seems to be the dominant brine transfer process.

Half-way through the observation period, the brine salinity became lower than that of the sea-water throughout the ice column. The brine network therefore switched to a "stratified" regime in which exchange with sea-water was limited to molecular diffusion, strongly stabilizing the bulk mean sea-ice salinity. During the transition between the two regimes, and in areas closer to ridges, slush water (resulting from a mixture of snow meltwater and sea water accumulated at the snow-ice interface) penetrated through the growing "honeycomb-like structure" and replaced the downward draining brines. This resulted in a slight local replenishment of nutrients (as indicated by dissolved silicic acid). However, as a whole, the described decaying regime in this globally unflooded location with limited snow cover should be unfavorable to the development of healthy and active surface and internal microbial communities.

The switch from gravity to diffusion controlled transport mechanisms within the ice column also should affect the efficiency of gas exchange across the sea-ice cover. The observed late build-up of a continuous, impermeable, superimposed ice layer should further significantly hamper gas exchange.

Statistical estimates of the evolution of the ice thickness during the observation period and salinity trends of the under-ice water salinity down to $30 \mathrm{~m}$ corroborate model predictions of a moderate bottom melting $(5-10 \mathrm{~cm})$ from ocean heat fluxes.
\end{abstract}

(C) 2008 Elsevier Ltd. All rights reserved.

Keywords: Antarctic; Sea Ice; Weddell Sea; Summer decay; Brine network; Temporal evolution

\footnotetext{
*Corresponding author.

E-mail address: jtison@ulb.ac.be (J.-L. Tison).

${ }^{1}$ Now at Department of Earth \& Atmospheric Sciences at University of Alberta, Edmonton, Canada.
}

\section{Introduction}

Sea ice in both hemispheres covers between 18 and 28 millions $\mathrm{km}^{2}$ in the course of a single year, an area range that compares with the largest biomes on Earth (IPCC, 2001). Because of its peculiar properties and large 
variations in seasonal extent, sea ice influences the global climate system through a suite of large-scale processes, including albedo fluctuations, insulation between the ocean and the atmosphere, production of deep-water, stratification of the surface waters during spring melting and seeding primary production in the marginal ice zone (e.g., Jacobs and Weiss, 1998; Jeffries, 1998; Lizotte and Arrigo, 1998; Thomas and Dieckmann, 2003). Further, recent work (Semiletov et al., 2004; Delille, 2006) has demonstrated the usual assumption that the sea-ice cover is a barrier to gas exchange between the upper ocean and the atmosphere might need to be reconsidered for ice temperatures greater than $-10^{\circ} \mathrm{C}$ (Gosink et al., 1976). This impinges on the fluxes of climatically important gases $\left(\mathrm{CO}_{2}, \mathrm{DMS}, \mathrm{CH}_{4}\right)$.

Sea ice hosts a complex web of microorganisms, which have adapted to its specific physico-chemical constraints. The resident biological community consumes and produces biogases, which gives sea ice a controlling role in gas exchange between the ocean and the atmosphere. The impact of these potentially important processes is unknown and has led to an increasing number of studies on the biogeochemistry of sea ice in the past two decades (Thomas and Dieckmann, 2003), with initiation of dedicated interdisciplinary research programs aiming at improving our understanding of the physical and biogeochemical properties of growing and decaying sea ice, and their potential impact on the air-ice-ocean fluxes of climatically significant gases in the polar seas. A further objective is to model these processes and scale them up to a global level.

This paper focuses on the time series of the main physico-chemical properties of an $80-90 \mathrm{~cm}$ thick first-year sea-ice cover section of the ISPOL floe. Understanding better the processes that govern the decay of Antarctic firstyear sea ice is of primary importance to biogeochemical studies, because they profoundly affect the environment in which the spring/summer sea ice and surface sea-water microbial activity occurs. Sea-ice decay has been best studied in the Arctic (Untersteiner, 1968; Weeks and Ackley, 1986; Eicken et al., 2000; Johnston, 2006) but only described in terms of salinity and stable isotopes $\left(\delta^{18} \mathrm{O}\right)$ in the Antarctic (e.g. Eicken, 1998). More work is needed to help develop a conceptual and, ultimately, a numerical model of meltwater and brine transport through sea ice (Eicken, 2003). It has been shown that the most effective desalination process in the Arctic is "meltwater flushing", a process in which the hydraulic head created by snow and ice meltwater produced at the top surface flushes downwards the resident brine. How much of this process is active in the Antarctic, where summer melting is generally less extensive than in the Arctic, is not known. Clearly, surface snow melting is large enough to produce layers of superimposed ice at intermediate levels in the snow cover, where the temperature is still below the melting point and meltwater refreezes (e.g., Haas et al., 2001; Kawamura et al., 2004). A more developed situation occurs when the amount of melting is large enough for the meltwater to reach the snow-sea ice interface, where superimposed ice will then eventually form under a double-diffusion process. In the latter, snow melt at the temperature of the melting point will loose heat an order of magnitude faster than it gains salt from the underlying sea ice brine (also at its melting point), and therefore freeze at the interface (Morris and Jeffries, 2001; Haas et al., 2001; Kawamura et al., 2004). Snow thickness and wetness also will play an important role in controlling the sea-ice decay process. Thick snow will favor negative freeboard (snow-sea ice interface below sea level) and induce sea-water flooding of the floe surface. Contrary to winter conditions, when the low temperature of the snow will induce sea-water freezing and snow-ice formation, the sea-water will remain liquid in the summer and mix with surface snow at the snow-sea ice interface to form "slush". Although tracer studies in the Arctic have shown that both vertical and lateral transport of meltwater occur in the sea-ice cover (Eicken et al., 2002), yet it is not clear which process dominates flooding in permeable summer Antarctic ice (i.e. lateral flow from ridged areas or leads nearby vs. vertical transfer of sea water from below). Reduced snow thickness and/or water occurrence at the ice surface will reduce the albedo and favor heat absorption in the upper ice layers. Eventually, as the season progresses, upper ice temperatures and related fractional brine volumes ( $V_{\text {brine }} / V_{\text {bulk ice }}$ ) will increase to reach the connectivity threshold of about $5 \%$ (Buckley and Trodahl, 1987; Golden et al., 1998). In the early stages of decay, brine salinity should still be above sea-water value, inducing density instability within the brine network. The aim of this ISPOL early summer time-series study is to understand how the density instability will be resolved (gravity-driven brine drainage and convection with underlying sea-water, or, brine flushing under hydraulic head), how will the brine network then evolve with further warming as summer proceeds, and what the consequences should be for the biogeochemical evolution of the sea-ice cover.

\section{Study site, material and methods}

\subsection{Choice of the site}

ISPOL took place in the Western Weddell Sea, at approximately $68^{\circ} \mathrm{S}$ and $55^{\circ} \mathrm{W}$. During the 5-week observation period, the floe drifted about $100 \mathrm{~km}$ northward and $20 \mathrm{~km}$ to the west. The ISPOL floe was located at the boundary between a band of second-year ice in the East and a band of thick first-year ice originating from the Ronne polynya in the West (Fig. 1, Hellmer et al., 2006).

A major concern for this study was the selection of an unflooded (positive freeboard), level first-year sea-ice section, in order to keep processes as simple as possible. Extensive surveys of ice and snow thickness revealed that the majority of the ISPOL floe consisted of thick secondyear ice, with ice and snow thicknesses between 1.8 and $2.3 \mathrm{~m}$, and 0.6 and $0.9 \mathrm{~m}$, respectively (Haas et al., 2008). 


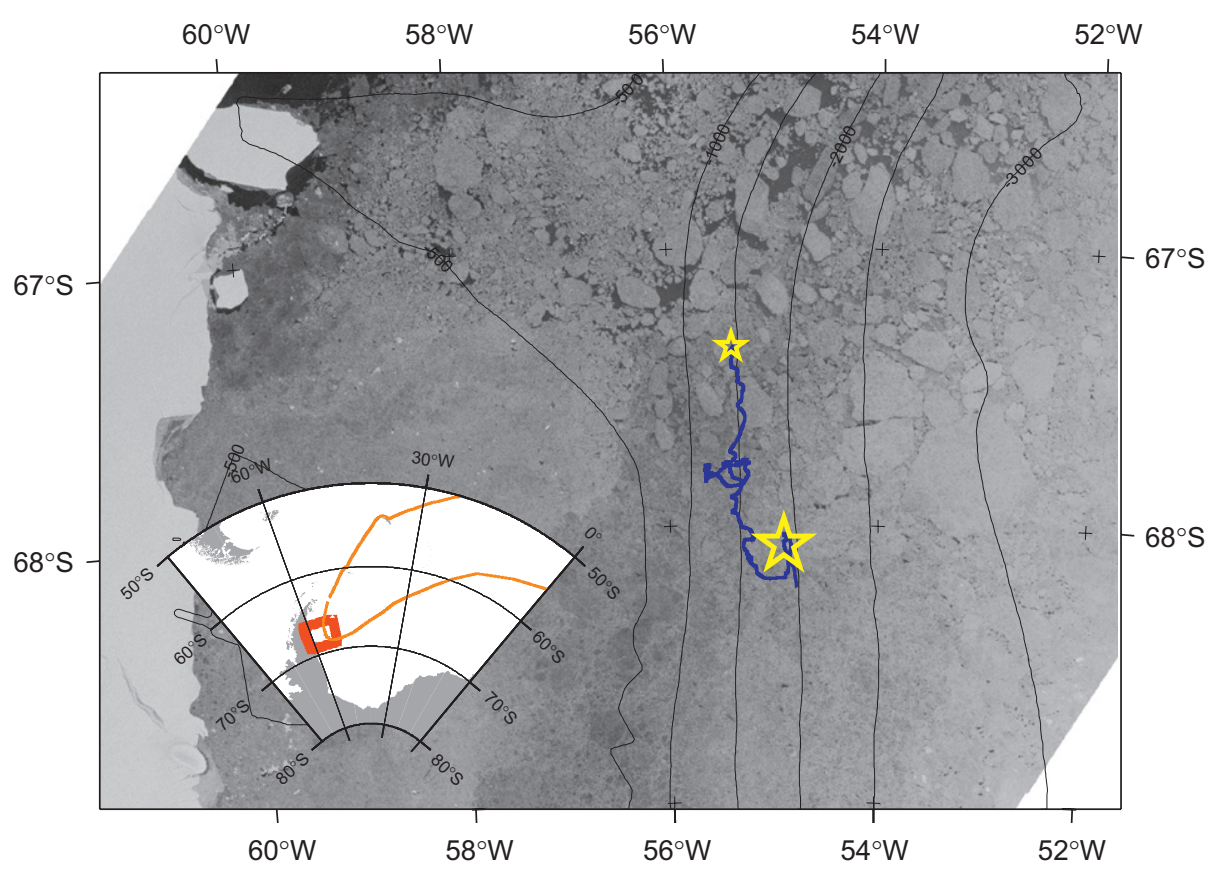

Fig. 1. Envisat synthetic aperture radar image acquired on 30 November 2005, showing the Ice Station Polarstern (ISPOL) study area in the Western Weddell Sea (inset, plus cruise track) and the start (27 November 2004, large yellow star) and end points (2 January 2005, small yellow star) of the drift. The western border coincides with the Larsen-C ice front; the northern boundary is close to the sea ice edge. Black contours show water depth in meters. Note the north-south extent of a dark appearing band of first-year sea ice at about $56^{\circ} \mathrm{W}$ (from Hellmer et al., 2006).

Consequently, most ice had negative freeboard and was partially flooded. However, between areas of second-year ice, a network of refrozen leads and cracks extended with ice thicknesses of $0.8-0.9$ and $0.1-0.25 \mathrm{~m}$ of snow, which resulted in a clear secondary mode in the thickness distribution.

A $70 \times 30 \mathrm{~m}$ area ("clean site" in Fig. $2 \mathrm{~A}$ and B) was selected in this first-year ice, with a positive freeboard of a few centimeters, for the duration of the experiment. Its perimeter was naturally delimited by ridges. Within the area, smaller adjacent $5 \times 5 \mathrm{~m}$ units were chosen for regular sampling at about 5-day intervals (number and color scheme in Fig. 3A). On each sampling day, a first half of the unit was dedicated to ice-core sampling and the other half to brine sampling from holes drilled in the ice and insitu measurements (Fig. 3B). Usually, the hole from the first ice-core retrieval was used for sea-water sampling.

\subsection{Working procedure at the clean site}

All operations were conducted wearing clean garments (Tyvek overalls, overshoes and polyethylene gloves). First, snow was collected in polyethylene containers using polypropylene shovels. Then ice cores were retrieved using a specially designed electropolished stainless-steel corer that has been shown to allow trace metal clean sampling (Lannuzel et al., 2006). Cores were immediately wrapped in $\mathrm{PE}$ bags and stored on the sampling site in an insulated box filled with individual cooling bags, pre-cooled at $-30^{\circ} \mathrm{C}$, in order to limit brine drainage from samples as much as possible. Holes were drilled into the ice cover at 20 and
$60 \mathrm{~cm}$ depth, to allow gravity-driven brine collection (the sackholes sampling technique, Thomas and Dieckmann, 2003). Brine from the ice core was collected as well as under ice sea-water at interface, 1 and $30 \mathrm{~m}$ depth using a portable peristaltic pump (Cole-Palmer, Masterflex E/P).

Sampling was carried out on seven occasions, between 29.11.04 and 30.12.04, at regular intervals (usually every five days). On each sampling day, about 14 ice cores were retrieved, about $20 \mathrm{~cm}$ apart from each other, and 24 sackholes drilled. These allowed the measurement of a full range of physical and biogeochemical variables among which only temperature, crystal fabric, bulk salinity, and water stable isotopes will be discussed here.

\subsection{Methods}

Ice temperature was measured in-situ directly after extraction of the cores, using a calibrated probe (TESTO 720 ) inserted in pre-drilled holes (perpendicular to core sides) at the exact diameter of the probe and with a depth resolution of $5-10 \mathrm{~cm}$. Precision of the measurements was $\pm 0.1^{\circ} \mathrm{C}$ (not including potential bias from heat transfer on drilling).

Bulk ice-salinity measurements were done on two different kinds of samples, to investigate the dependence of the measured salinity on sample size. On board, melted ice samples were usually collected from successive 5 -cmthick slices of a dedicated ice core, with a diameter of $14 \mathrm{~cm}$, and were measured with a portable salinometer with a precision of \pm 0.1 . Bulk ice-salinity measurements also were performed back in the home laboratory, on "twin" 
(A)

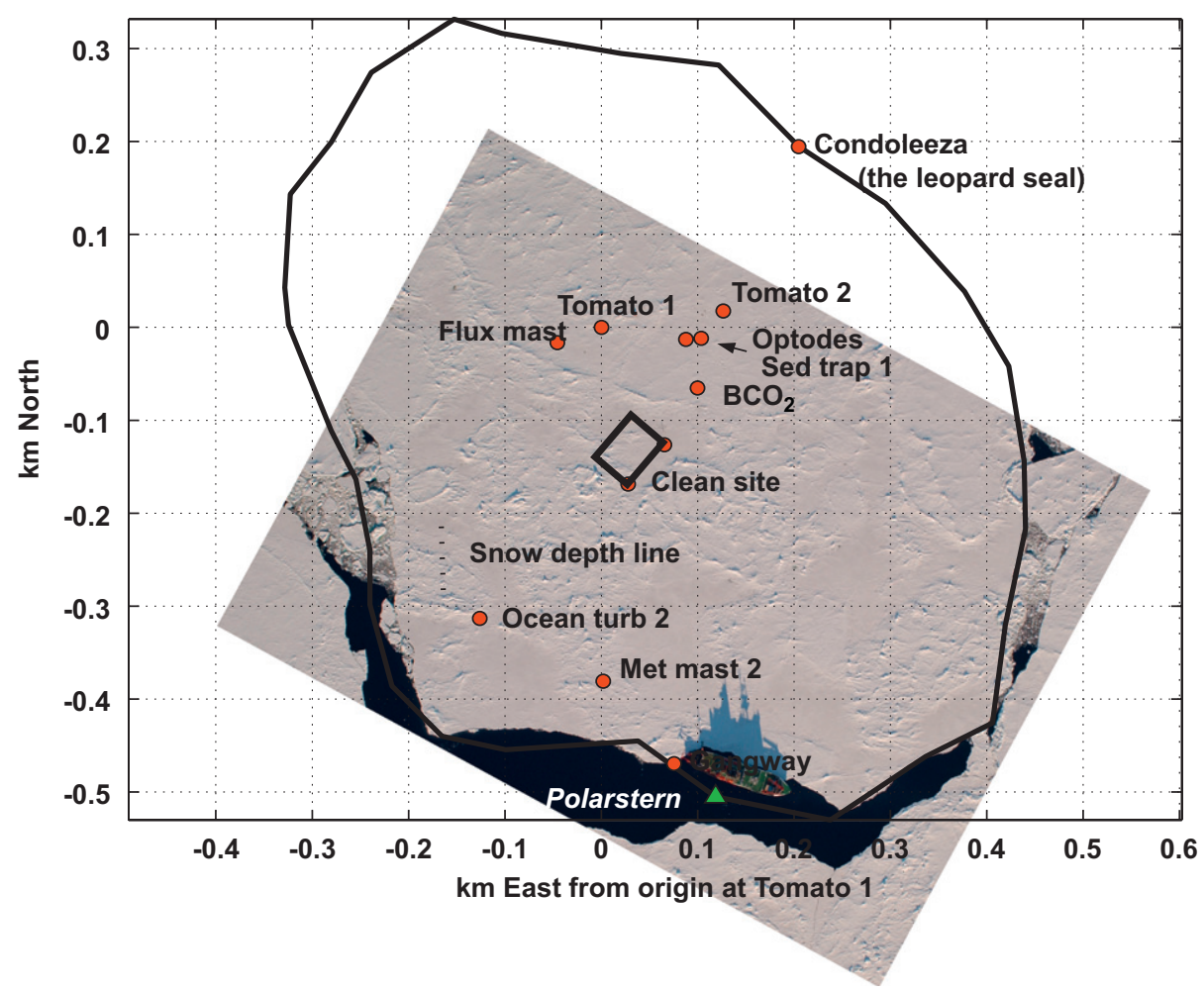

(B)

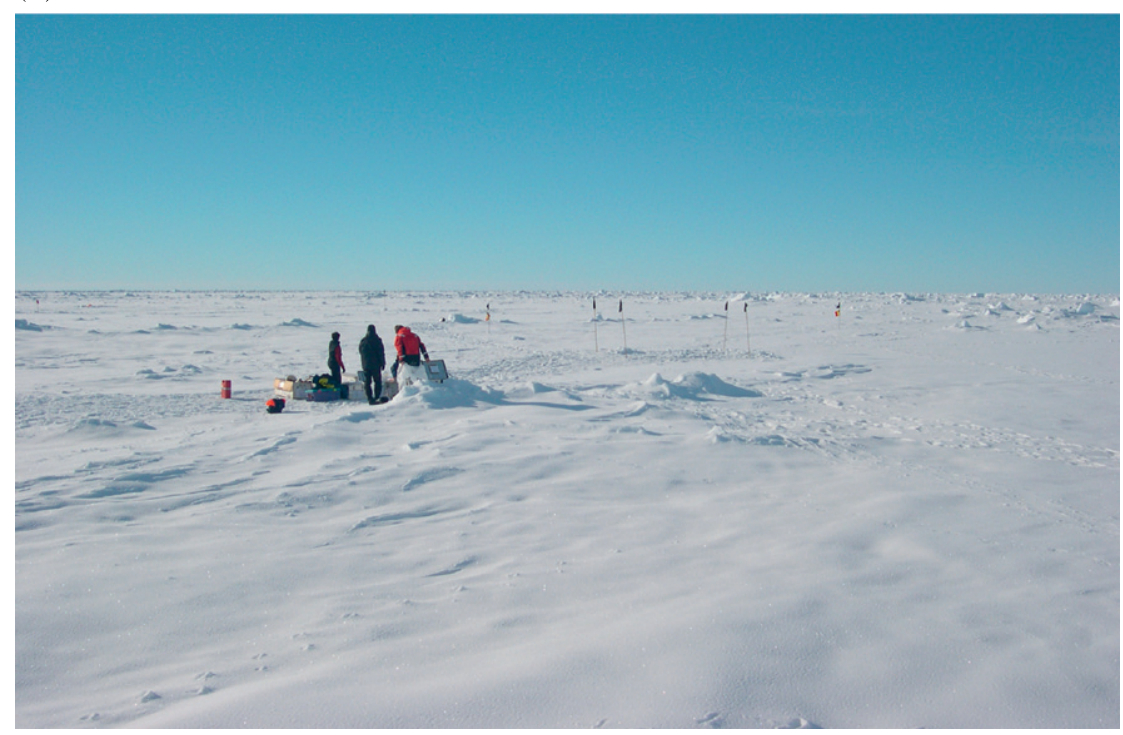

Fig. 2. (A) Clean site location on the ISPOL floe and (B) general view from the loading area. Note the prominent ridges surrounding the sampling site. GPS referenced location map courtesy M. McPhee.

cores from the same sampling day. These were kept below $-25^{\circ} \mathrm{C}$ at all times during transport and storage, therefore preventing post-sampling brine drainage. Two datasets were recovered: one from successive thin vertical samples at $5 \mathrm{~cm}$ resolution (about $20 \mathrm{ml}$ ), and the other from regularly spaced discontinuous ( $4 \mathrm{~cm}$ apart) 1 -cm-thick horizontal slices (about $100 \mathrm{ml}$ ). In both cases, salinity was determined using a Radiometer Titrilab TIM 870 conductimeter and a calibration curve from diluted aliquots of an IAPSO (10) salinity standard. Comparison of the "on-board" vs. "laboratory" salinity measurements provides insights into the required minimum amount of sample to ensure reliable bulk salinity values. Fig. 4A shows the ranges of salinity profiles on 29.11.04, obtained from the three different sample volumes. Clearly, large amounts such as those collected in the field, on a dedicated ice core, are necessary to ensure the reliability of the measurements. Note also that the vertical cuts show less variability than the 
horizontal ones, probably because the first have less probability to include large, horizontally discrete, porosity features such as brine channels.

In order to gain accuracy in the measurements, under-ice sea-water salinity was measured on samples stored in sealed bottles and brought back to the University of Liège. Salinity was then determined with a Guildline-Autosal induction salinometer with an accuracy of \pm 0.003 .

Ice thick sections were cut on board the R.V. Polarstern for ice texture observations such as, banding, brine channels, holes and bubble density. Thin sections also were studied in the home cold room laboratory $\left(-30^{\circ} \mathrm{C}\right)$ on another nearby core, using the standard procedure developed by Langway (1958).

One-way analysis of variance (ANOVA) was performed on the ice-core length dataset for testing the equality of the

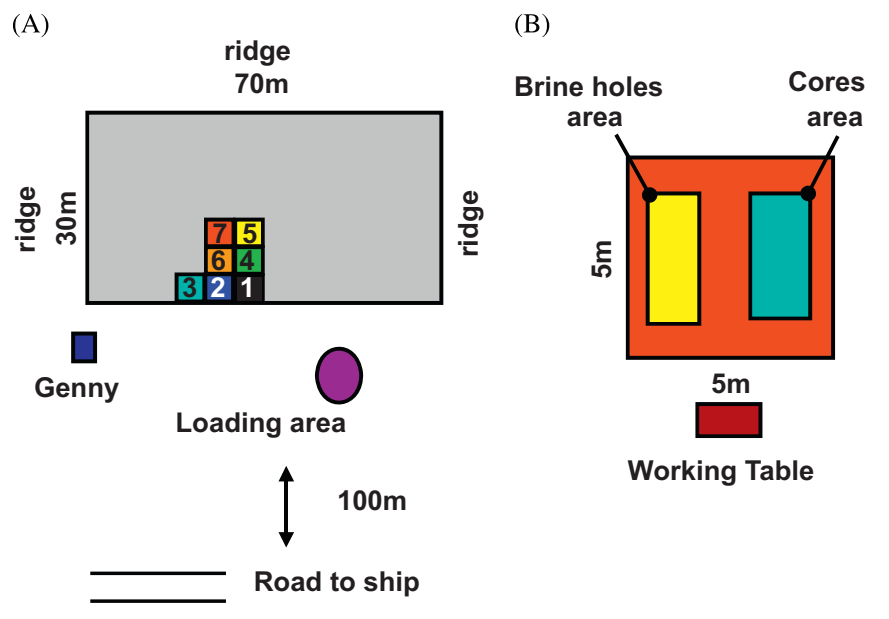

Fig. 3. Clean site-sampling strategy: (A) overall sampling strategy and (B) daily sampling scheme. Numbers and color schemes in (A) refer to the time series. population means at different time. The method of orthogonal contrast (Dagnelie, 1998) was then used to look for a possible temporal trend in the mean sea-ice cover thickness.

Water aliquots $(10 \mathrm{ml})$ were collected from the melted ice samples dedicated to the bulk salinity measurements to perform for $\delta^{18} \mathrm{O}$ measurements at the Australian Antarctic CRC. Isotope ratios were measured with a dual-inlet VG SIRA mass spectrometer using the conventional water$\mathrm{CO}_{2}$ equilibration method. Accuracy with respect to VSMOW is $\pm 0.12 \%$.

Major nutrients, including dissolved silica, which is shown in this paper, were measured on board. Silicic acid was determined using standard colorimetric methodology (Grasshoff et al., 1983) as adapted for flow injection analysis (FIA) on a LACHAT Instruments Quick-Chem 8000 autoanalyzer (Hales et al., 2004) with a precision better than $5 \%$.

\section{Results}

Fig. 5 gives an overview of ice texture at the ISPOL clean site between 29.11.04 and 30.12.04. All cores had a top 6- to 14-cm layer of granular ice underlain by columnar ice down to the bottom of the ice column. Examination of the upper $10 \mathrm{~cm}$ of the cores from the second half of the period (Fig. 5B-14.12.04 to 30.12.04) showed the occurrence of layers of coarser, elongated, bubble-free ice crystals. Largescale porosity features are clearly becoming dominant in the upper $40 \mathrm{~cm}$ of the sea-ice cover as time goes by. Freeboard was always positive, although generally small $(+5$ to $+1 \mathrm{~cm}$, red numbers in Fig. 5A). Snow thickness ranged from 6 to $25 \mathrm{~cm}$, and was generally lower than values observed in other sections of the ISPOL floe (0.6-0.9 m, Haas et al., 2008). There was no clear sign of
(A)

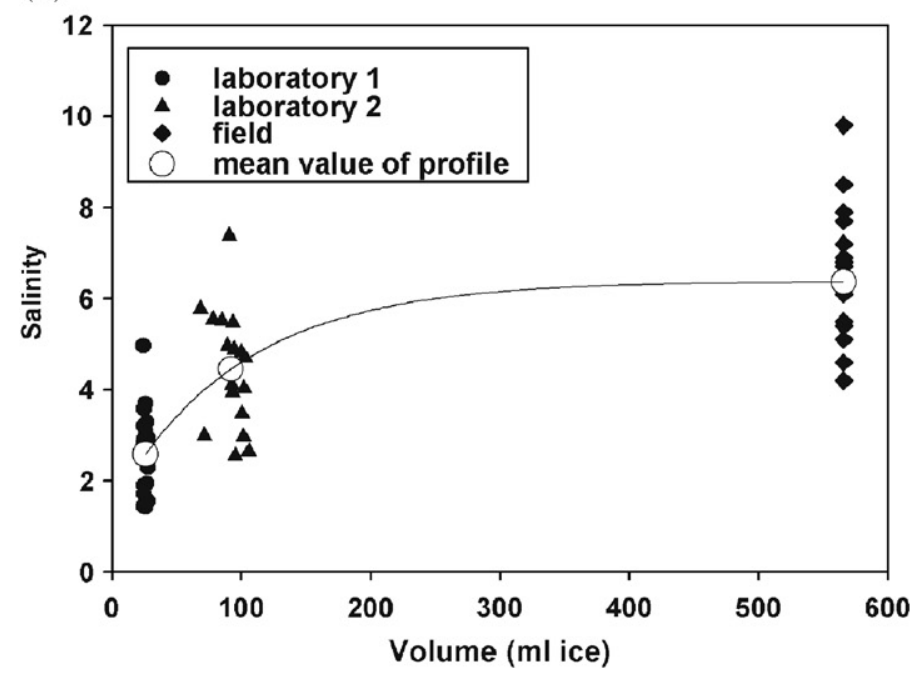

(B)
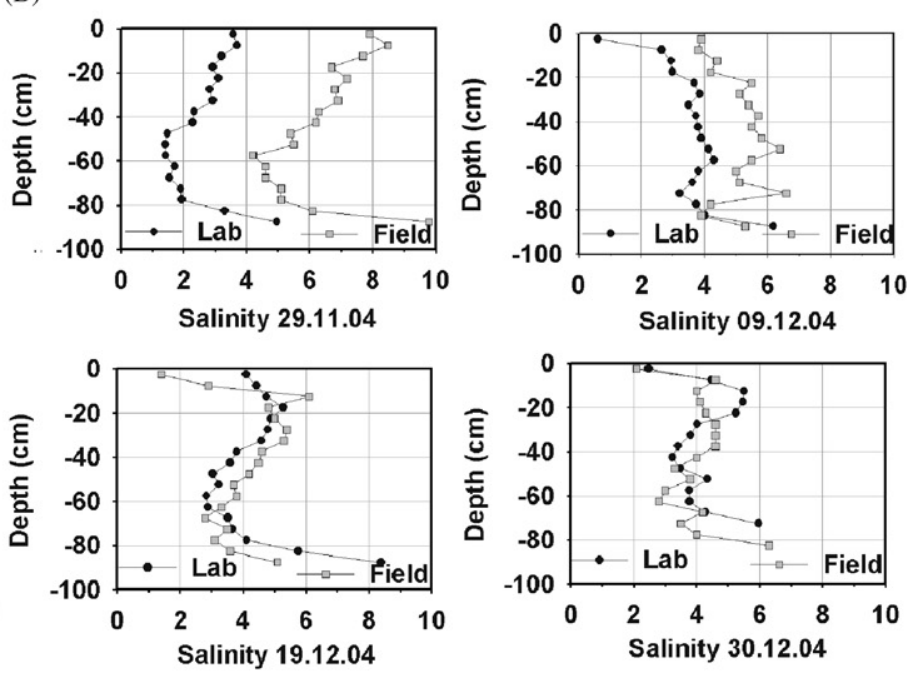

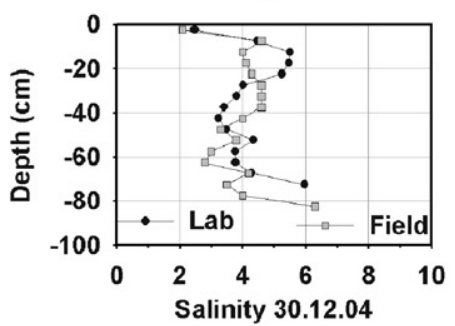

Fig. 4. (A) Bulk ice salinity profiles obtained with increasing sample volume and different sample orientation for ISPOL station 1 (29.11.04-"laboratory $1 "=$ continuous vertical samples, "laboratory $2 "=$ discontinuous horizontal sampling, "field" = continuous horizontal sampling) and (B) comparison between laboratory (vertical, $20 \mathrm{ml}$ ) and field (continuous horizontal, $575 \mathrm{ml}$ ) bulk ice salinity measurements at four illustrative sampling times. See text for details. 


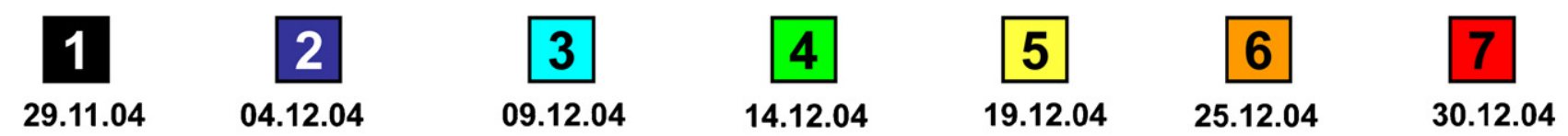

(A)
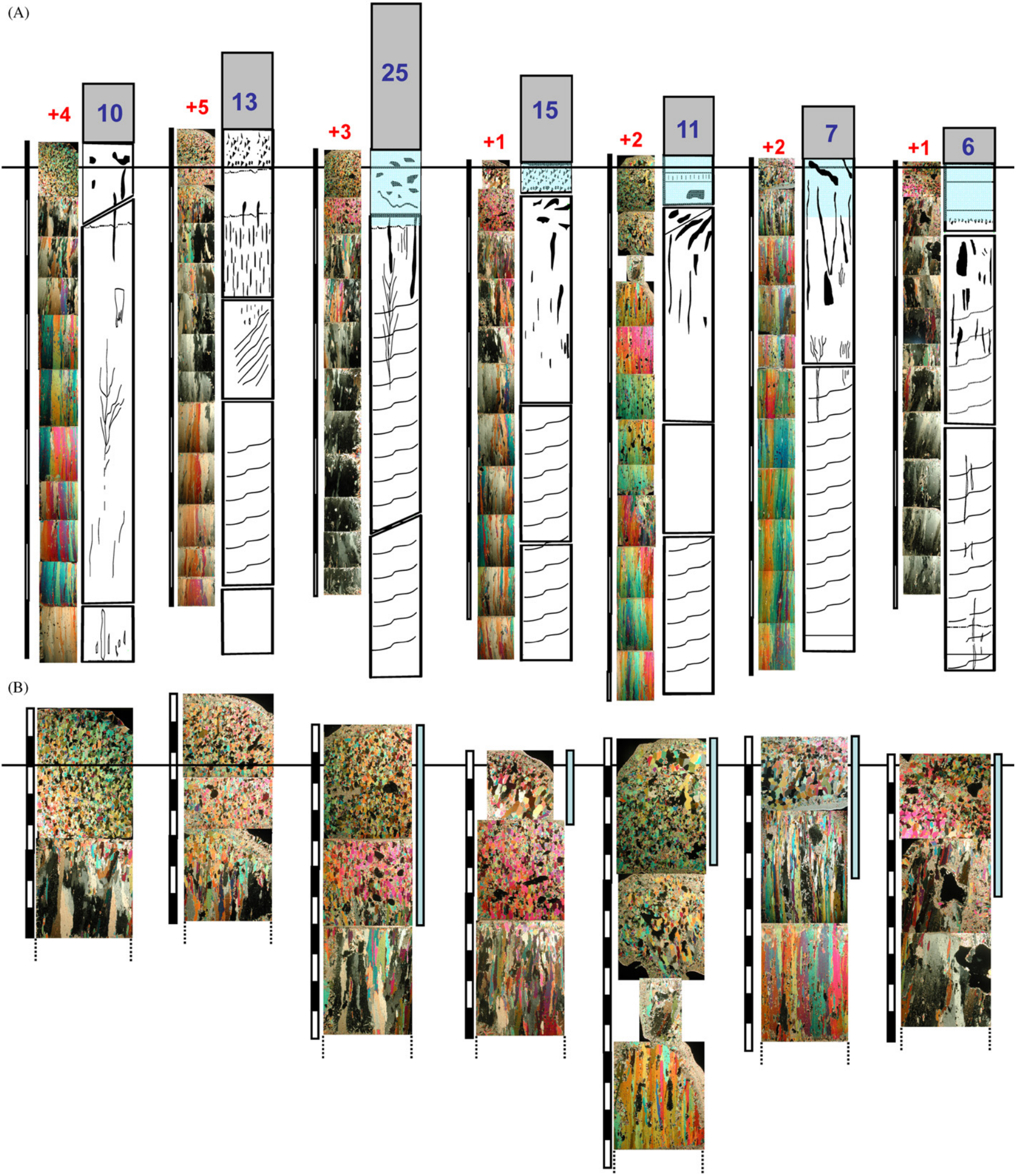

Fig. 5. Textural properties of the ice-core time series at the ISPOL clean site: (A) overview in vertical thin sections under crossed polarizers (texture core) and half core description on-board R.V. Polarstern (DMS core), (B) enlargement of the top part of the cores showing the development of superimposed ice and of the "honeycomb structure". Upper scale unit $=10 \mathrm{~cm}$, lower scale unit $=2 \mathrm{~cm}$. Blue shading shows areas with $\delta^{18} \mathrm{O}$ lower than sea-water value, indicating a snow contribution. Red numbers are freeboard $(\mathrm{cm})$ and blue numbers, snow thickness $(\mathrm{cm})$. Black horizontal line is sea level (see text for details). 
flooding, although the ice surface appeared occasionally "wetted".

Ice temperature was on the whole quite warm, ranging from -3.1 to $-0.2^{\circ} \mathrm{C}$ (Fig. 6A). Times series of the temperature depth profiles showed that the ice cover was warming up with time, with increasing amplitude of changes observed closer to the surface. The temperature trend with depth reverted on 09.12.04, with the occurrence of a temperature minimum at $55 \mathrm{~cm}$ depth on that date.

Bulk "on-board" salinity at the ISPOL "clean site" (Fig. 6B) switched from the typical C-shape to a Z-shape profile in the course of time, with the strongest decrease in the upper half of the ice cover. Although great care was taken to limit brine drainage during sampling (see above), we cannot rule out brine losses, especially from the very porous surface layers, at the end of the experiment. Again, the salinity profile observed on 09.12.04 is somewhat peculiar, with a steadily increasing salinity with depth and a saltier $45-80 \mathrm{~cm}$ section.

Calculated brine salinity and brine volumes, hypothesizing thermodynamic equilibrium of the brine (Cox and Weeks, 1983; Leppäranta and Manninen, 1988; Eicken, 2003), are illustrated in Fig. 6C and D, respectively. Brine salinity ranged from 48 to 8 for the whole experiment. As expected from the temperature and salinity trends described above, it was regularly decreasing with time, with the largest changes occurring in the upper half of the seaice cover. The two first sampling days showed brine salinity higher or equal to the sea-water value (34.20-34.40) while profiles from the last four sampling days were below it, with record minimum salinity values of 8 in the surface layer. The 09.12 .04 profile was transitional, with a brine salinity maximum of 37 at $55 \mathrm{~cm}$ depth, similar to the value observed in the layers above on the previous sampling event (04.12.04).

Fig. 6C also shows, as open triangles, brine salinity observed in the sackholes for the $0-20$ and $0-60 \mathrm{~cm}$ integrated depth ranges.

Calculated brine volumes (Fig. 6D) ranged from 9\% to $32 \%$. It is noted that these are likely to be minimal estimates, since the bulk ice salinity might have been biased by brine loss on sampling, especially in the top and bottom sections. The highest values were observed in the upper half of the ice cover, which also exhibited the highest level of changes, corroborating the visual observations of gradually increasing voids in the ice textures. The brine volume was more stable with time, at $10-15 \%$, in the lower half of the ice cover, to the expected exception of the very bottom layer showing much higher values. Another exception is again sampling day 09.12.04, with no depth trend, and consistently higher values in the lower $50 \mathrm{~cm}$.

Fig. $6 \mathrm{E}$ and $\mathrm{F}$ (detail) shows the $\delta^{18} \mathrm{O}_{\text {bulk ice }}$ depth profiles. Surface snow had an isotopic composition range from $-13 \%$ to $-17 \%$ while the $\delta^{18} \mathrm{O}$ of slush (with a salinity of 27), collected on the flanks of a ridge nearby, was about $-7.5 \%$. Bottom water fluctuates slightly around $-0.5 \%$ (mean: $-0.47 \%$, sd: $\pm 0.06 \%$ ). Bulk ice values are generally consistent between sampling days, increasing from $+0.7 \%$ at the surface to +1.9 at the bottom, with, however, two noticeable exceptions. Firstly, more negative values in the top $15 \mathrm{~cm}$ of the ice cover and, secondly, sampling day 09.12.04, which shows significantly more negative $\delta^{18} \mathrm{O}_{\text {bulk ice }}$ values at all depths, except for the very bottom.

\section{Discussion}

Despite the fact that we have paid attention to (a) study a level ice floe with a homogeneous surface and (b) sample small contiguous areas, we must acknowledge here that a time series such as this one may be affected by spatial variability that could not be assessed. This should therefore be kept in mind when we discuss the evolutionary processes of the sea-ice cover. On similar grounds, one might wonder if, despite the reasonable distances kept between areas dedicated to consecutive sampling days, previous ice-core sampling operations could have affected results from the subsequent sampling days. Although this is difficult to assess, neither temperature, nor calculated or observed brine salinities indicated detectable effects of disturbed heat fluxes or sea-water infiltration processes.

All cores show a typical textural sequence of first-year pack ice: surface granular ice underlain by dominant columnar ice. Isotopic $\delta^{18} \mathrm{O}$ composition of the ice (Fig. 6E and $\mathrm{F}$ ) shows that part of the granular ice is actually "snow-ice" resulting from refrozen sea-water infiltration in snow (blue shading in Fig. 5), with an isotopic signature below the mean sea-water value (Lange et al., 1990; Eicken et al., 1994; Jeffries et al., 1994, 1997; Eicken, 1998). Furthermore, the occurrence of coarser, elongated, bubblefree ice crystal embedded in the granular ice is typical of "superimposed ice" formed by refrozen snow melt (Morris and Jeffries, 2001; Haas et al., 2001; Kawamura et al., 2004).

Ice thickness evolution as seen in Fig. 5A does not indicate a clear trend of basal melting, as would be expected from heat flux measurements at the ice-ocean interface at other locations on the floe (McPhee, 2008). The spatial variability at a given observation time (comparing the thin sections textural core to the half-core description of the DMS core on board Polarstern) is indeed apparently as large as the temporal variability, and in the range of the calculated thickness reduction from basal melting $(9-15 \mathrm{~cm}$ for the whole period, McPhee, 2008). However, the availability of a large number of cores for each of the sampling days (between 10 and 14) allows us to plot a mean thickness of the sea-ice cover as a function of time (Fig. 7, squares) and to use a statistical approach to test for a significant trend in these values. The result of the ANOVA test (level of significance $\alpha=0.05$ ) leads to the conclusion that there is a highly significant difference amongst the means of the ice-core lengths for the different time steps. Since the $p$-value related to the ANOVA $(p=0.003)$ is lower than the threshold of 0.01 in the present case, we can 
(A)

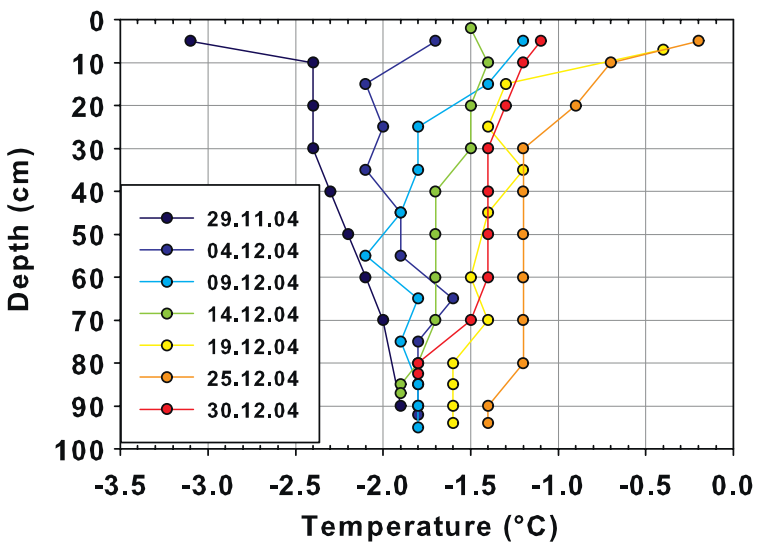

(C)

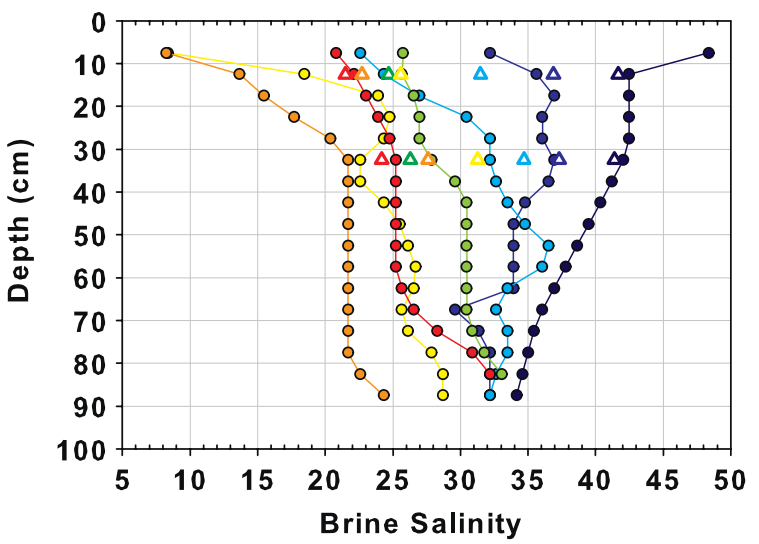

(E)

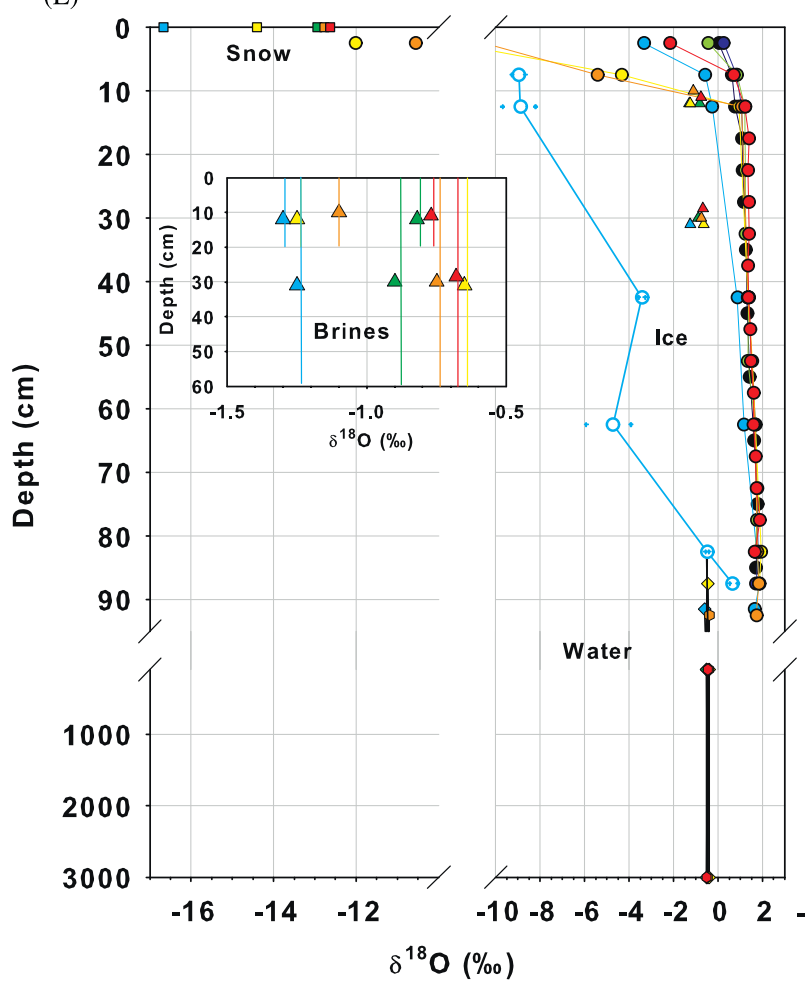

(B)

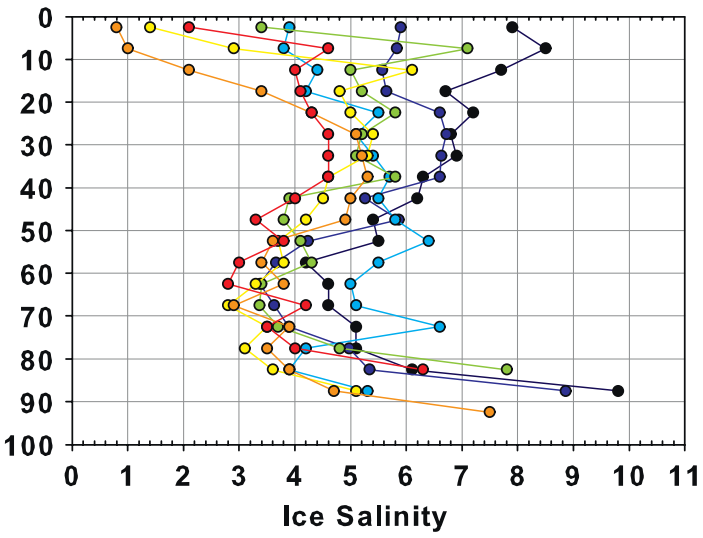

(D)

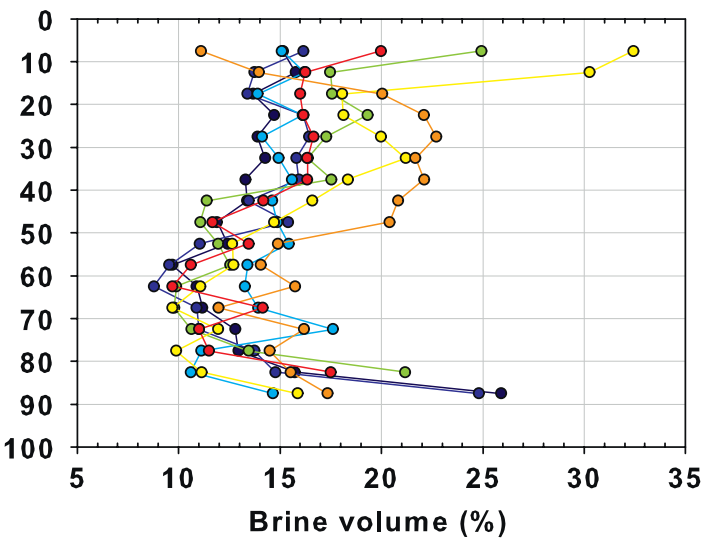

(F)
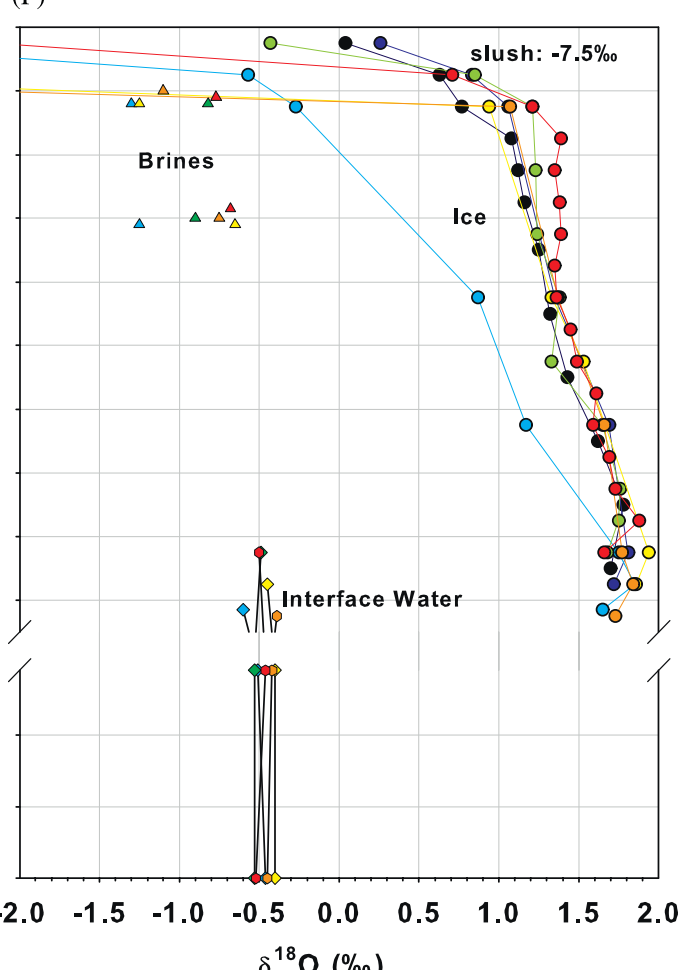

Fig. 6. Ice temperature (A), bulk ice salinity (B), theoretical (dots) and measurements within sackholes (open triangles at middle of depth range) brine salinities (C), theoretical brine volumes (D) and snow, ice, slush, brine and water $\delta^{18} \mathrm{O}(\mathrm{E})$ and $(\mathrm{F}$, detail) of the ice cores time series at the ISPOL clean site. Open circles and crosses in (E) are calculated $\Delta \delta^{18} \mathrm{O}$ brine, see text for details. 


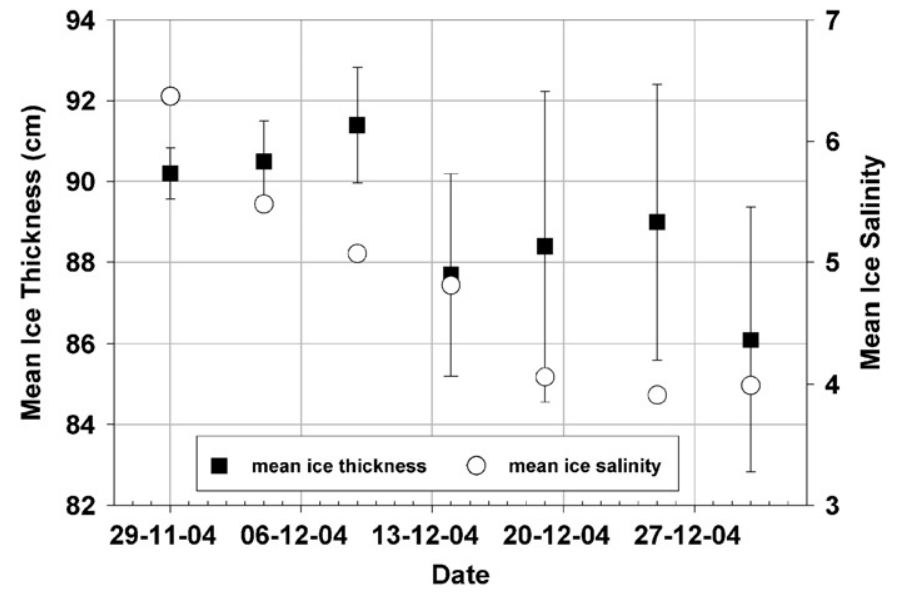

Fig. 7. Evolutions of mean ice thickness (black squares) and mean bulk ice salinity (open circles) for all ice cores of the ISPOL time series. Error bars on mean ice thickness are drawn at $\pm 1 \sigma$.

conclude the existence of a highly significant difference for one or more means. The method of orthogonal contrast was then applied to investigate a possible temporal trend in the means. The $p$-value related to the test $(p<0.001)$ for a linear decreasing trend of the mean sea-ice cover thickness with time reveals that the ice-core lengths data fit in a very highly significant way to the linear decreasing model. Finally, $1 \sigma$ error bars on ice thickness are clearly increasing with time, supporting the idea that basal melting increases the ice-water interface roughness.

Melting does not only affect the ice-ocean interface. Both thin sections and thick sections show a clear degradation of the cores structure in their upper half $(0-40 \mathrm{~cm})$, with an increasing proportion of large pores and holes in the ice texture over the course of the survey.

The temperature profile at the start of the experiment (Fig. 6A, 29.11.04) was inherited from typical winter conditions, with lower temperatures in the upper parts of the ice column, but all temperatures were already well above the reference temperature of $-5^{\circ} \mathrm{C}$, that would indicate restored connectivity ( $5 \%$ relative brine volume) for bulk ice salinity above 5 (the so-called "law of fives", Buckley and Trodahl, 1987; Golden et al., 1998). As indicated above, relative brine volume (Fig. 6D) was always above $9 \%$ and reached more than $30 \%$ within the surface layers.

The temperature and salinity trends observed at our ISPOL "clean site" were very similar to those recently described for first-year ice in the Arctic during the first months of decay (May-June, Johnston, 2006). Meltwater flushing during ice warming and decay and resultant drastic changes in the temperature and salinity profiles over the entire ice column are a common feature in Arctic sea ice. However Eicken (1992) reported that this process is not important in Antarctic sea ice from the Weddell Sea, and usually restricted to second-year and multi-year ice, but nevertheless depending on the time of the year and on the distance from the ice edge. Our observations show that
Antarctic first-year sea ice can be affected by important changes in temperature and salinity profiles during its decay process. It is also interesting to note that, as shown in Fig. 4B, where profiles from 20- and 575-ml samples are compared for the various time slices, the bias from reduced salinity sample volume decreases as the ice decays. This is in accordance with experimental observations in tank ice (Interice experiment 1) from Cottier et al. (1999) who have demonstrated the decoupling between zones of high salinity and brine location as impurities relocate in warming sea ice, smoothing out the initial heterogeneity.

The mean ice-core salinity is plotted in Fig. 7 (open circles). It shows a clear decrease during the first half of the experiment and a stable value at about 4 for the last three sampling days.

Calculated brine salinity (Fig. 6C) decreased with time to values below sea-water salinity about halfway through the experiment, suggesting a transition from unstable to stable density profiles in the brine network. Since calculated brine volumes were all well above the threshold value of $5 \%$ for impermeable ice (Buckley and Trodahl, 1987; Golden et al., 1998) from the very beginning of the survey, connectivity is ensured within the brine network and helps explaining the trend of the mean ice salinity in Fig. 7. Brine drainage under the unstable density profile leads to desalination in the first half of the observation period while density stratification limits further brine loss in the second half of the study period.

It is also worth comparing the calculated brine salinities to those observed in the sackholes for the $0-20$ and $0-60 \mathrm{~cm}$ depth ranges (triangles in Fig. 6C). There is a good agreement between the two values for the first two sampling days, in the shallower holes. Discrepancies tend to increase during the observation period, suggesting either a potential limitation of the accuracy of the ice temperature measurements (used in the calculation) in a porous ice medium or that the system is not in thermodynamic equilibrium. The values of the lower sackholes are clearly not representative, most likely because these holes are integrating brines drained from the upper layers.

The lower $\delta^{18} \mathrm{O}$ values in the upper $15 \mathrm{~cm}$ of ice column indicate variable contribution of snow ice or superimposed ice, as also seen in the textures in Fig. 5.

Since the ice cover is in a general state of decay and since there is no fractionation on pure-ice melting (Jouzel and Souchez, 1982; Souchez and Jouzel, 1984), the peculiar isotopic profile at sampling day 09.12 .04 can only be related to changes in the isotopic composition of brine in an open system (brine migration or brine loss). A first order estimate of the differences in brine isotopic composition $\left(\Delta \delta^{18} \mathrm{O}_{\text {brine }}\right)$ between sampling day 09.12 .04 and the other sampling occasions/locations can be deduced from the differences in $\delta^{18} \mathrm{O}_{\text {bulk ice, }}$, considering that the $\delta^{18} \mathrm{O}_{\text {pure ice }}$ did not change in the course of time and neither did the relative brine volume. The latter assertion is clearly not true, but since the relative change in relative brine volume is reasonably small, especially in the early stages of the 
experiment, we can use it for a first estimate of the $\Delta \delta^{18} \mathrm{O}_{\text {brine, }}$ e.g., by comparing profiles of 04.12 .04 and 09.12.04. The result is shown in Fig. 6E as open circles (using mean brine volume for the 04.12.04-09.12.04 period at a given depth) and crosses (using either of relative brine volumes on 04.12 .04 and 09.12 .04 ). This gives a $\Delta \delta^{18} \mathrm{O}_{\text {brine }}$ profile ranging between $-9 \%$ and $+0.5 \%$, with a clear decrease of its absolute value with depth. Such a lowering of the isotopic composition of brine can only result from infiltration of water contaminated by snow or snow ice meltwater. Three potential candidates can be pointed at: (a) internal melting of the snow ice layer $\left(-3.5 \%<\delta^{18} \mathrm{O}\right.$ $<-0.5 \%$ ), which is present at the site location (Figs. 5 and $6 \mathrm{E}$ ), (b) snow melt from the surface $\left(-17 \%<<\delta^{18} \mathrm{O}\right.$ $<-13 \%$ ), and (c) lateral infiltration of the slush that forms in the areas closer to the ridges $\left(\delta^{18} \mathrm{O}_{\text {slush }}=-7.5 \%\right.$ ). It also should be noted that, although within the range of two error bars, the interface sea-water value is the lowest on 09.12.04 (Fig. 6F).

Note that the calculated differences in brine isotopic values clearly imply much lower $\delta^{18} \mathrm{O}_{\text {brine }}$ values than those observed in the sackholes brines (triangles in Fig. 6E and F). This could be explained by the fact that the sackhole sampling procedure biases $\delta^{18} \mathrm{O}_{\text {brine }}$ toward less negative values because of surface melting and increased contribution from the crystal melt. The 09.12.04 sackhole brine $\delta^{18} \mathrm{O}$ is, however, the lowest in the range.

Finally, comparing the initial (29.11.04, black line) and final $\left(30.12 .04\right.$, red line) $\delta^{18} \mathrm{O}_{\text {bulk ice }}$ profiles above $60 \mathrm{~cm}$ depth, it is interesting to note that the final bulk ice signature is always higher than the initial. Following the same rationale as above, i.e. that these changes can only be related to changes in the isotopic composition of the brine, suggests that, in areas not influenced by surface slush infiltration, the initially lighter brine (resulting from interface isotopic fractionation on freezing that enriches the solid phase in the heavier isotope and the interface liquid in the lighter one (e.g., Souchez and Jouzel, 1984; Tison and Haren, 1989; Souchez et al., 1989; Eicken, 1998)) is progressively replaced by pure-ice melt, with a heavier signature.

\subsection{A model for the temporal evolution of the sea-ice cover}

We are now able to describe the temporal evolution of the first-year sea-ice cover at the ISPOL "clean site", using the dataset described above, as sketched in Fig. 8. At the beginning of the observation period, the brine network is unstable in terms of density and already largely interconnected. This should favor downward brine migration, either through convection (where downward brine movement in some areas is counterbalanced by upward seawater movement in others) or brine drainage (where downward brine movement is compensated by melting/ infiltration in the upper layers), and results in the observed regular mean ice salinity drop for the three first sampling days. The isotopic record at sampling day 09.12.04 does not support a convective process. Indeed, because of the isotopic fractionation occurring on ice growth (Jouzel and Souchez, 1982; Souchez and Jouzel, 1984; Tison and Haren, 1989; Souchez et al., 1989; Eicken, 1998), the brine isotopic signal will always be more negative than (or equal to) the mean sea-water signature $(-0.5 \%)$. Therefore, replacing part of the initial brine with sea-water would inevitably shift the bulk ice $\delta^{18} \mathrm{O}$ towards less negative values. This is the reverse of the observed trend from 04.12.04 to 09.12.04. As surface brine travels downward, it is progressively replaced by either sea water/snow slush from the flooded ridges flanks nearby (sampling day 09.12.04 is the closest to the ridges bordering the "clean site" patch-Figs. 2B and 3A, and show the thickest snow layer, inherited from previous snow fall and wind drift accumulation-Fig. 5) or by in-situ melting as the temperature increases, particularly in the upper layers. Direct snow-melt contribution to brine channel infiltration, away from the ridges, is probably a very limited source since below-zero temperatures at the snow-ice interface

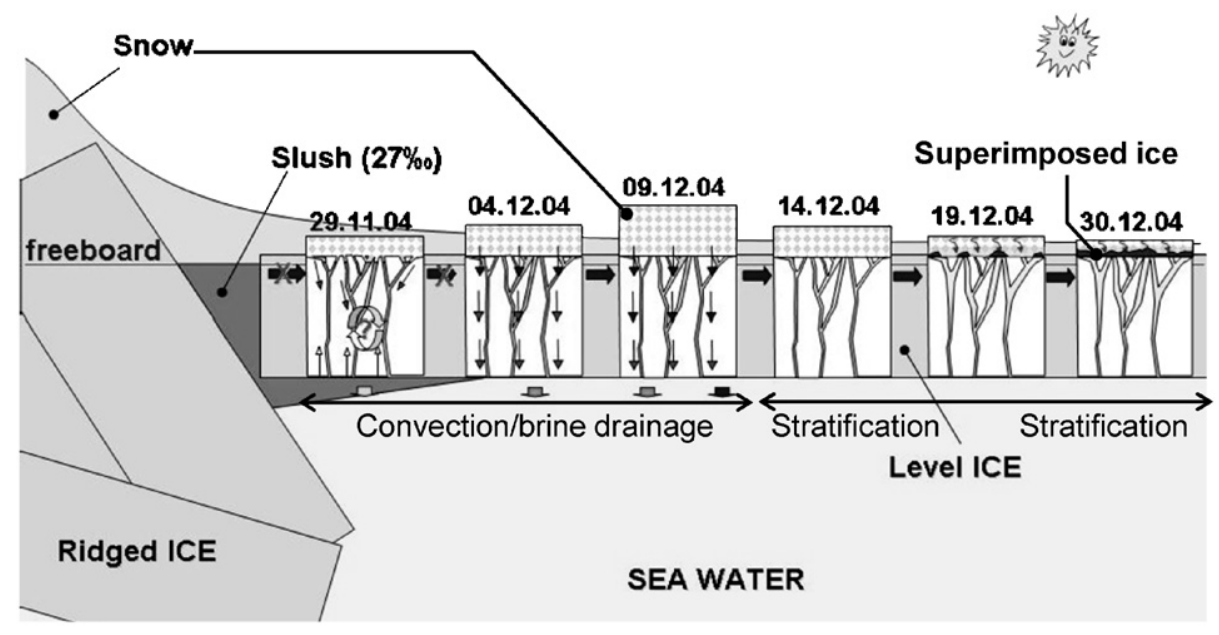

Fig. 8. A simple model for the degradation of the first-year level sea-ice cover at the ISPOL clean site. 
were the rule, as shown by the superimposed ice formation at the end of the period (Fig. 5B) and by extensive direct temperature measurements at other locations on the ice floe. The already large porosity of about $14 \%$ greatly favors brine transfer, not only vertically, but also potentially laterally from the ridges nearby, through the building "honeycomb-like" structure. Indeed, the snow cover at sampling day 09.12.04 (with its clear infiltration signature) did not show any sign of slush build up at the snow-ice interface. Note that, in that case, the profile at sampling day 09.12.04 would typically illustrate interference of spatial variability within a time-series study. As discussed above, we cannot preclude, however, that the more negative $\delta^{18} \mathrm{O}$ value observed in the brine is a contribution from in situ melting of the upper part of the snow-ice layer. Considering a mean brine volume of $15 \%$ on the $09.12 .04,13 \mathrm{~cm}$ snow ice melt would be required to fully "refill" the existing brine network. Observed snow-ice thicknesses are compatible with this value, though rather on the high side. However, since reduction in snow-ice thickness has not been observed prior to 09.12.04, snow-ice melt is probably not the only contributor. Finally, one could argue that snow ice is also present at sampling days 4-7 (Fig. 5) and that no sign of infiltration of brines with lower $\delta^{18} \mathrm{O}$ is seen there (Fig. $6 \mathrm{E}$ and $\mathrm{F}$ ). As we have seen, brine dynamics has undergone major changes halfway through the experiment and the initiation of brine stratification would have hampered downwards infiltration of snow ice-melt, making sampling day 09.12.04 a singular case.

Of particular importance, from a biogeochemical perspective, is the actual process of brine migration. Brine convection or sea-water/snow-slush invasion from the surface layer (a first step towards flooding) will favor nutrient replenishment and potentially boost the development of the surface and/or internal microbial community. Internal melting of channel walls will, on the contrary, dilute nutrients and eventually destroy algae anchoring sites. Nutrients records, as illustrated for dissolved silica in Fig. 9, did not indicate replenishment during the first half of the observation period (29.11.04, black symbols; 04.12.04, dark blue symbols). Apart from those in the skeletal layer (samples shown with crosses in Fig. 9A), all data points were below the conservative sea-water dilution curve (Fig. 9A), with a clear trend of decreasing concentrations between 29.11.04 and 04.12.04 (Fig. 9B). Only at sampling day 09.12.04 was the concentration slightly higher in the upper half of the ice cover, probably reflecting the surface slush infiltration, without, however, recovering the sea-water dilution curve silica concentration within the brine. This example, and the behavior of a suite of other variables (including other nutrients) that will be described elsewhere, suggest that brine drainage (as opposed to brine convection with sea-water upwards movement within the sea-ice cover) was the dominant process of desalination in the early stages of decay. Since no obvious flooding occurred on site (before and apart from the local event on 09.12.04) and the freeboard was
(A)

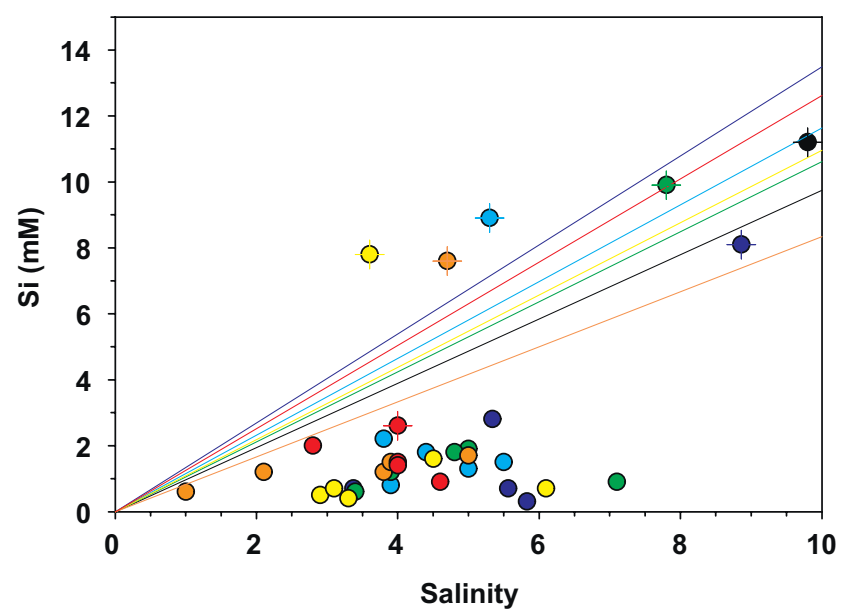

(B)

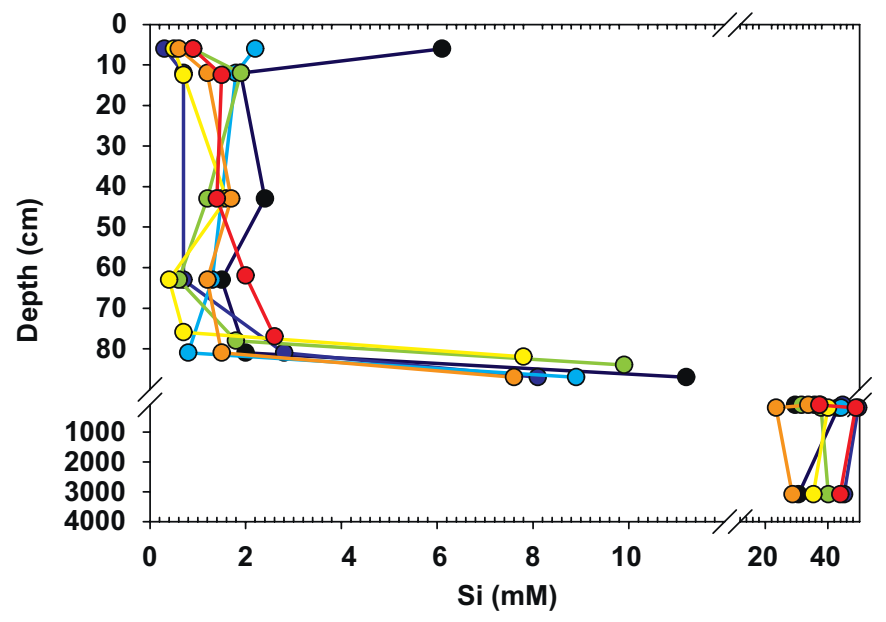

Fig. 9. Evolution of the dissolved silica concentration in all ice cores for the ISPOL time series: (A) samples position vs. conservative dilution curves of sea-water, (B) depth profiles in ice and underlying water. Each dilution curve describes the theoretical evolution of the Si concentration in sea-water when it is progressively diluted by melting pure ice. To draw the dilution lines, the mean $\mathrm{Si}$ value of the underlying water has been used at each sampling occurrence. If $\mathrm{Si}$ behaves conservatively, bulk ice samples should lie on the dilution curve. Any consumption process (such as biological uptake of nutrients) would bring the bulk ice samples below the dilution curve and vice versa. Note the dominant pattern of substantial undersaturation, apart for the ice-water interface samples (crosses).

positive ( +5 to $+3 \mathrm{~cm}$ in the first half of the period), one has to attribute the brine drainage process to the slight hydraulic head that must have resulted from increased melting in the surface layers above the freeboard.

As brine salinity dropped below the sea-water value, stratification of the brine network occurred, and solute exchange should now be mainly controlled by molecular diffusion along concentration gradients, especially as the freeboard level was getting close to zero. Fig. 10 shows a clear trend of decreasing salinity in the surface sea-waters, and, if this is attributable to exchange with the regional decaying sea ice drifting north, the dilution must have resulted from basal or lateral melting of the sea-ice cover (eventually increased in areas of brash and floe/lead 


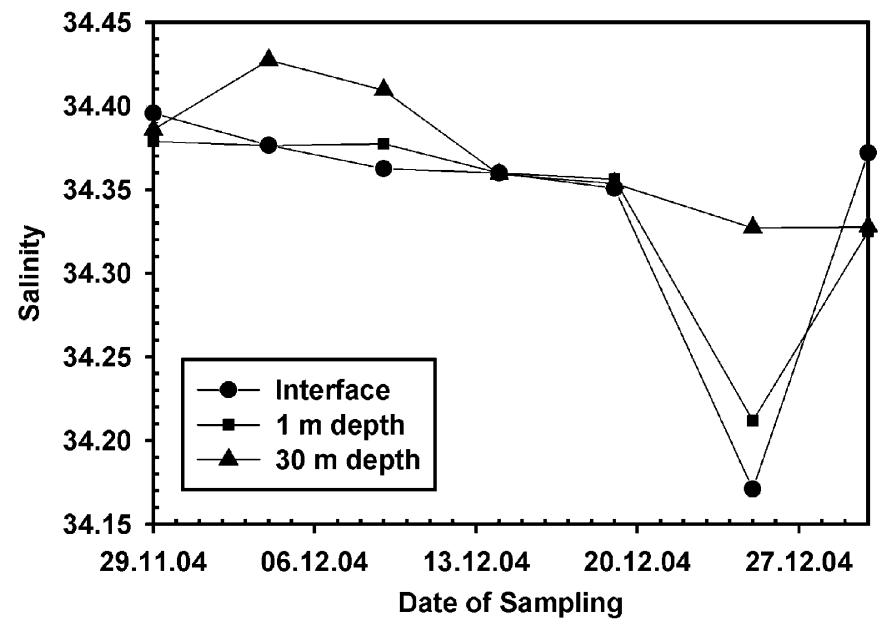

Fig. 10. Evolution of the salinity of the underlying water at the "clean site" in the course of the ISPOL experiment. Note that the measurements were only made at three discrete depths (ice-water interface, 1 and $30 \mathrm{~m}$ ). See text for details.

edges - see, e.g., 25.12.04 at interface and $1 \mathrm{~m}$ depth), since no further desalination is observed in the mean ice-core salinity record. This melting process resulted in the observed diminishing trend of the sea-ice thickness (Fig. 7). Finally, textural observations (Fig. 5B) indicate that superimposed ice formation started in the second half of the study period, as melting surface snow infiltrated and refroze at the top of the more saline and colder granular ice. This process is also of interest from a biogeochemical perspective, because it will impede gas exchange with the atmosphere, by giving rise to an impermeable layer of superimposed ice. A pause in the downward flux of $\mathrm{CO}_{2}$ into the ice was observed on the site for the last two sampling days whereas breaking the existing superimposed ice crust immediately re-established the flux (Delille and Tison, unpubl. data).

\section{Conclusions}

Regular five-day sampling of the main physico-chemical properties of an unflooded 90 -cm-thick first-year sea-ice cover at ISPOL during spring/early summer 2004 has provided insights into the changing character of sea ice during the summer decay season, and the processes involved. Progressive melting occurs both in the top layers and at the ice-ocean interface. In the first case, internal melting largely dominates resulting in a strong increase of the ice porosity, while interface melting dominates in the latter.

In the early stages of decay, brine salinity in the upper layers is higher than sea-water resulting in density instability. This favors downward brine migration, as attested by the steady decrease of the mean bulk-ice salinity. Bulk-ice salinity depth profiles and brine salinity measurements during the first three sampling days clearly showed downward salt transfer, with replacement by fresher brine in the upper layers. The driver of the brine migration was likely brine drainage under the hydraulic head resulting from increased melting in the upper sea-ice layers, as well as enhanced horizontal and vertical brine transfer favored by the large porosity. Closer to the ridged areas, local events of downward slush infiltration were detected, although there were no signs of flooding at the surface, suggesting sub-surface transfer occurs through the building up of a "honeycomb-like" structure (Haas et al., 2001). Convection processes involving the underlying seawater were less likely, as indicated by the $\delta^{18} \mathrm{O}$ values of the brine and because nutrient replenishment of the internal layers was not observed.

Further surface and internal melting leads to brine salinity that is lower than sea-water throughout the sea-ice cover, which stratifies the brine medium and ends the drainage process, limiting the exchange of solutes via molecular diffusion. As a result, and since the freeboard is close to zero (and therefore strongly limiting the potential for an efficient hydraulic head), the bulk ice salinity and the salinity profiles stabilized. The contribution of sea-ice melting to the underlying sea-water is then mainly limited to the ice-ocean interface.

In a way, this second phase of internal sea-ice cover decay is a preliminary stage of the more extensive case of melt ponds conditions in the Arctic.

This overall process of decay, in the (near) absence of flooding, is of utmost importance for the ice biogeochemical evolution since it would limit nutrient replenishment and compromise brine channel wall stability, therefore impeding the development of surface and internal algal communities. The situation is likely to be very different in areas where a thicker snow cover would favor flooding by depressing the freeboard to below sea-water level (i.e. negative freeboard). The observation of an infiltration event at sampling day 09.12.04 suggests that, if flooding occurred during this early summer stage in the evolution of the sea ice, it would mainly result from lateral sources, rather than bottom-up water transfer. The latter case would indeed be restricted to the cases where ice submergence from snow fall events or bottom melting would induce upward brine/water movement by the amount of submergence.

The switch from a brine drainage to a diffusion controlled transfer of solutes within the ice column, together with the late build-up of a continuous superimposed ice layer, should also considerably affect gas exchange in this generally highly porous medium, but this is outside the scope of the present paper.

Although the thickness of the snow cover and local meteorological conditions will undoubtedly control the timing of the decay process and the potential for flooding, we believe that the processes described here should apply to a large number of other locations around Antarctica since more than $80 \%$ of the Antarctic sea ice cover is made of level first-year pack ice. It is, however, clear that future work should focus on both the effects of flooding and the evolution of multiyear floes. Increased surface and internal 
melting as summer progresses should further reduce brine and bulk ice salinity profiles. Should the ice survive the summer, the resulting second-year ice would display low salinity "I"-shaped profiles, as documented by Eicken (1992) in the Weddell Sea or Remy et al. (in press) in McMurdo Sound during the B-15 iceberg stranding event.

\section{References}

Buckley, R.G., Trodahl, H.J., 1987. Thermally driven changes in the optical properties of sea ice. Cold Region Science and Technology 14, 201-204.

Cottier, F., Eicken, H., Wadhams, P., 1999. Linkages between salinity and brine channel distribution in young sea ice. Journal of Geophysical Research 104 (C7), 15859-15871.

Cox, G.F.N., Weeks, W.F., 1983. Equations for determining the gas and brine volumes in sea ice samples. Journal of Glaciology 29, 306-316.

Dagnelie, P., 1998. Statistique Théorique et Appliquée: Tome 2: Inférence Statistique à une et à deux dimensions. Bruxelles, De Boeck, 659pp.

Delille, B., 2006. Inorganic Carbon dynamics and air-ice-sea $\mathrm{CO}_{2}$ fluxes in the open and coastal waters of the Southern Ocean, Ph.D. Thesis, University of Liège.

Eicken, H., 1992. Salinity profiles of Antarctic sea ice: field data and model results. Journal of Geophysical Research 97, 15545-15557.

Eicken, H., 1998. Deriving modes and rates of ice growth in the Weddell Sea from microstructural, salinity and stable-isotope data. In: Jeffries, M. (Ed.), Antarctic Sea Ice: Physical Processes, Interactions and Variability, American Geophysical Union, vol. 74. Antarctic Research Series, Washington, DC, pp. 89-122.

Eicken, H., 2003. From the microscopic to the macroscopic, to the regional scale: growth, microstructure and properties of sea ice. In Thomas, D.N., Dieckmann, G.S. (Eds.), Sea Ice-An Introduction to its Physics, Chemistry, Biology and Geology. Blackwell, Oxford, UK, pp. $22-82$.

Eicken, H., Lange, M.A., Hubberten, H.-W., Wadhams, P., 1994. Characteristics and distribution patterns of snow and meteoric ice in the Weddell Sea and their contribution to the mass balance of sea ice. Annales Geophysicae 12, 80-93.

Eicken, H., Bock, C., Wittig, R., Miller, H., Poertner, H.O., 2000. Magnetic resonance imaging of sea ice pore fluids: methods and thermal evolution of pore microstructure. Cold Regions Science and Technology 31, 207-225.

Eicken, H., Krouse, H.R., Kadko, D., Perovich, D.K., 2002. Tracer studies of pathways and rates of meltwater transport through Arctic summer sea ice. Journal of Geophysical Research 107 (10), 8046.

Golden, K.M., Ackley, S.F., Lytle, V.I., 1998. The percolation phase transition in sea ice. Science 282, 2238-2241.

Gosink, T.A., Pearson, J.G., Kelley, J.J., 1976. Gas movement through sea ice. Nature 263, 41-42.

Grasshoff, K., Ehrhardt, M., Kremling, K., 1983. Methods of Seawater Analysis. Verlag Chemie, Weinheim, Germany.

Haas, C., Thomas, D.N., Bareiss, J., 2001. Surface properties and processes of perennial Antarctic sea ice in summer. Journal of Glaciology 47 (179), 613-625.

Haas, C., Nicolaus, M., Willmes, S., Worby, A., Flinspach, D., 2008. Sea ice and snow thickness and physical properties of an ice floe in the western Weddell Sea and their changes during spring warming. DeepSea Research II, this issue [doi:10.1016/j.dsr2.2007.12.020].

Hales, B., van Greer, A., Takahashi, T., 2004. High-frequency measurements of seawater chemistry: flow-injection analysis of macronutrients. Limnology and Oceanography: Methods 2, 91-101.

Hellmer, H.H., Haas, C., Dieckmann, G.S., Schröder, M., 2006. Sea ice feedbacks observed in Western Weddell Sea. Eos 87, 173-184.

IPCC, 2001. Climate Change 2001: The Scientific Basis, Intergovernmental Panel on Climate Change, 〈www.ipcc.ch $\rangle$.
Jacobs, S., Weiss, R., 1998. Ocean, Ice and Atmosphere: Interactions at the Antarctic Continental Margin, Antarctic Research Series, vol. 75. American Geophysical Union, p. 380.

Jeffries, M. (Ed.), 1998. Antarctic Sea Ice: Physical Processes, Interactions and Variability, Antarctic Research Series, vol. 74. American Geophysical Union, p. 407.

Jeffries, M.O., Shaw, R.A., Morris, K., Veazey, A.L., Krouse, H.R., 1994. Crystal structure, stable isotopes $\left(\delta^{18} \mathrm{O}\right)$ and development of sea ice in the Ross, Amundsen and Bellingshausen seas, Antarctica. Journal of Geophysical Research 99, 985-995.

Jeffries, M.O., Worby, A.P., Morris, K., Week, W.F., 1997. Seasonal variations in the properties and structural composition of sea ice and snow cover in the Bellingshausen and Amundsen seas, Antarctica. Journal of Glaciology 43, 138-151.

Johnston, M., 2006. A comparison of physical properties and strength of decaying first-year ice in the Arctic and sub-Arctic. Annals of Glaciology 44, 154-162.

Jouzel, J., Souchez, R., 1982. Melting-refreezing at the glacier sole and the isotopic composition of the ice. Journal of Glaciology 28 (98), 35-42.

Kawamura, T., Jeffries, M.O., Tison, J.-L., Krouse, H.R., 2004. Superimposed ice formation in summer on Ross Sea pack ice floes. Annals of Glaciology 39, 563-568

Lange, M.A., Schlosser, P., Ackley, S.F., Wadhams, P., Dieckmann, G.S., 1990. ${ }^{18} \mathrm{O}$ concentrations in sea ice of the Weddell Sea, Antarctica. Journal of Glaciology 36, 315-323.

Langway, C.C., 1958. Ice fabrics and the Universal Stage. U.S. Army Snow Ice and Permafrost Research Establishment. Corps of Engineers, Technical Report 62, Wilmette, IL, USA.

Lannuzel, D., de Jong, J., Schoemann, V., Trevena, A., Tison, J.-L., Chou, L., 2006. Development of a sampling and flow injection analysis technique for iron determination in the sea ice environment. Analytica Chimica Acta 556 (2), 476-483.

Leppäranta, M., Manninen, T., 1988. The brine and gas content of sea ice with attention to low salinities and high temperatures. Finnish Institute of Marine Research Internal Report 88 (2), Helsinki, Finland.

Lizotte, M.P. and Arrigo, K.R. (Eds.), 1998. Antarctic Sea Ice: Biological Processes, Interactions and Variability, Antarctic Research Series, vol. 73. American Geophysical Union, p. 198.

McPhee, M.G., 2008. Physics of early summer ice/ocean exchanges in the Western Weddell Sea during ISPOL. Deep-Sea Research II, this issue [doi:10.1016/j.dsr2.2007.12.022].

Morris, K., Jeffries, M.O., 2001. Seasonal contrasts in snow-cover characteristics on Ross Sea ice floes. Annals of Glaciology 33, 61-68.

Remy, J.-P., Becquevort, S., Haskell, T.G., Tison, J.-L., in press. Impact of the B-15 iceberg "stranding event" on the physical and biological properties of sea ice in McMurdo Sound, Antarctica. Antarctic Science.

Semiletov, I., Makshtas, A., Akasofu, S.I., Andreas, F.L., 2004. Atmospheric $\mathrm{CO}_{2}$ balance: the role of Arctic sea ice. Geophysical Research Letters 31, L05121.

Souchez, R., Jouzel, J., 1984. On the isotopic composition in $\delta \mathrm{D}$ and $\delta^{18} \mathrm{O}$ of water and ice during freezing. Journal of Glaciology 30 (106), 369-372.

Souchez, R., Tison, J.-L., Jouzel, J., 1989. An isotopic method to estimate conductive heat flux through Antarctic first-year sea ice. Annals of Glaciology 14, 270-272.

Thomas, D.N., Dieckmann, G.S. (Eds.), 2003. Sea Ice: An Introduction to its Physics, Chemistry, Biology and Geology. Blackwell Science, Ltd., p. 402.

Tison, J.-L., Haren, J., 1989. Isotopic, chemical and crystallographic characteristics of first year sea ice from Breid Bay (Princess Ragnhild Coast-Antarctica). Antarctic Science 3, 261-268.

Untersteiner, N., 1968. Natural desalination and equilibrium salinity profile for perennial sea ice. Journal of Geophysical Research 73 (4), 1251-1257.

Weeks, W.F., Ackley, S.F., 1986. The growth, structure and properties of sea ice. In: Untersteiner, N. (Ed.), The Geophysics of Sea Ice. Plenum Press, New York, pp. 9-164. 